\title{
HIV and COVID-19 Co-Infection in an Urban Setting
}

\author{
Philip Lee ${ }^{1 *}$, Surksha Sirichand ${ }^{2}$, Luis Gonzalez Corro ${ }^{3}$, Nataly Rios Gutierrez ${ }^{4}$, Carlos Cruz ${ }^{5}$, Robert Grossberg ${ }^{6}$, and Raffaele M. Bernardo ${ }^{7}$
}

*Correspondence: phle@montefiore.org

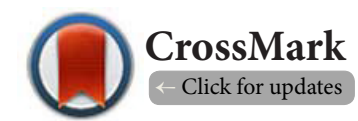

${ }^{1}$ Clinical Pharmacist, Pediatric Infectious Diseases, Children's Hospital at Montefiore, USA.

${ }^{2}$ Fellow, Department of Medicine (Infectious Diseases), Albert Einstein College of Medicine, USA.

${ }^{3}$ Medical Resident, Department of Medicine, Albert Einstein College of Medicine, USA.

${ }^{4}$ Study Coordinator, Department of Medicine, Albert Einstein College of Medicine, USA.

${ }^{5}$ Project Manager, Children's Hospital at Montefiore, USA.

${ }^{6}$ Associate Professor of Medicine (Infectious Diseases), Albert Einstein College of Medicine, USA.

${ }^{7}$ Assistant Professor of Medicine (Infectious Diseases), Albert Einstein College of Medicine, USA.

\begin{abstract}
Objective: The purpose of this study is to investigate potential factors associated with patient survival (primary outcome) and need for mechanical ventilation (secondary outcome) for people living with HIV (PLWH) who have COVID-19.

Design: This retrospective, observational cohort study was conducted from January 1, 2020 to April 30, 2020. Thirty-day readmissions were observed from January 1, 2020 to May 31, 2020.

Setting: Montefiore Medical Center is a large academic institution dispersed over three campuses located in Bronx County, NY. Bronx County has the highest prevalence of HIV in the United States, the fifthhighest prevalence of confirmed COVID-19 cases, and the fourth-highest prevalence of COVID-19 deaths across the United States, as of June 2020, according to the Johns Hopkins Coronavirus Resource Center. Participants: Patients were included in the cohort if they had an ICD-10 code corresponding to HIV infection (B20) and a positive severe acute respiratory syndrome coronavirus 2 (SARS-CoV-2) PCR test during the study period.

Main Outcome(s) and Measure(s): The primary outcome was survivorship. PLWH who survived COVID-19 were compared with those who did not. As a secondary outcome, PLWH who required mechanical ventilation were compared with those who did not.

Results: Seventy-two PLWH had positive SARS-CoV-2 PCR tests during the study period. Of these, 28 were female $(39 \%)$, and the median [IQR] age was $62[+/-16]$ years. The median CD4+ count was 235 cells/uL, and 11 patients $(15 \%)$ had an HIV viral load $</=200$ copies $/ \mathrm{mL}$. Twenty patients $(27.8 \%)$ did not survive. All 11 patients $(15 \%)$ who had a detectable HIV viral load at the start of the study period survived $(p=0.02)$. Patients who did not survive were more likely to have chronic kidney disease $(p<0.01)$, acute kidney injury $(\mathrm{p}<0.01)$, higher absolute neutrophil counts $(\mathrm{p}<0.01)$, and higher IL-6 levels $(\mathrm{p}<0.01)$ than those who survived. Fifteen patients $(20.8 \%)$ required mechanical ventilation, and three of those patients $(4.1 \%)$ survived. Patients who required mechanical ventilation were more likely to be obese $(\mathrm{p}<0.01)$ and to have higher absolute neutrophil counts $(\mathrm{p}=0.01)$ than those who did not need mechanical ventilation.

Conclusion: PLWH may be at higher risk of morbidity and mortality related to COVID-19 than the general population because of underlying co-morbidities. All patients in the study cohort who died had an undetectable HIV viral load; this finding suggests that patients with uncontrolled HIV are not at a higher risk of mortality than patients with controlled HIV in the setting of COVID-19.
\end{abstract}

Keywords: Covid-19, HIV, Survival

\section{Introduction}

The first case of the respiratory illness designated as Coronavirus
Disease-2019 (COVID-19) in the United States was reported on January 22, 2020 near Seattle, Washington [1]. Since then, the

(c) 2020 Lee et al; licensee Herbert Publications Ltd. This is an Open Access article distributed under the terms of Creative Commons Attribution License (http://creativecommons.org/licenses/by/3.0). This permits unrestricted use, distribution, and reproduction in any medium, provided the original work is properly cited. 
United States has emerged as an epicenter of the COVID-19 pandemic, with more than 6.8 million cases and over 200,000 deaths reported through September $23^{\text {rd }}, 2020$ [2]. Several risk factors-including advanced age, male sex, cerebrovascular disease, hypertension, obesity, chronic lung disease, diabetes mellitus, and cardiovascular disease-have been linked to increased likelihood of hospitalization and mortality [3,4].

As of December 2016, an estimated 1.1 million individuals in the United States were living with HIV [5]. People living with HIV (PLWH) may have an increased risk of poor outcomes from COVID-19 because of underlying immunosuppression [6] and a high prevalence of co-morbidities [7]; however, limited data are available to describe COVID-19 and its outcomes in PLWH [8-11]. Incidence of HIV and COVID-19 are increasingly concentrated in overlapping at-risk populations; therefore, it is vital to understand the intersection of these two illnesses.

Bronx County, New York has the highest prevalence of PLWH $(1,781$ per 100,000 residents) in the United States [12]. Of the five boroughs of New York City, the Bronx has been the most severely affected by COVID-19, with a case rate of 3,107 per 100,000 residents [13]. Here we describe a cohort of persons living with HIV hospitalized at our institution with COVID-19. We hypothesize that patients with uncontrolled HIV infection, namely a detectable viral load or a CD4 count below 200, would have a higher mortality rate and need for mechanical ventilation compared to their controlled HIV counterparts.

\section{Methods}

We conducted a retrospective chart review from January 1 , 2020 to May 1, 2020. We included patients admitted to our institution who carried a diagnosis of HIV/AIDS, were at least 18 years old, and were found to have a positive SARS-CoV-2 PCR during their hospitalization. Thirty day readmissions were collected until May 31,2020. Our primary and secondary endpoint was survival and the need for mechanical ventilation, respectively.

All complete blood counts were collected within 48 hours of admission. Any inflammatory markers (i.e. interleukin-6, procalcitonin and C-reactive protein) represent the first value obtained at any time during admission. HIV-RNA and T-cell subsets were recorded either during the admission, within 6 months of admission, or both if available. Respiratory status was recorded as the maximal oxygen supplementation requirement during their admission. We defined chronic pulmonary disease as patients with a history of asthma, COPD, or bronchiectasis. These values, along with demographic information, were recorded in the electronic medical record.

Patients were classified as having mild, moderate, or severe disease. Patients with mild disease were maintained on room air throughout their admission with or without chest radiograph abnormalities. Patients were classified as moderate disease if they required nasal cannula (NC) or non-rebreather (NRB) oxygen supplementation at any point during their hospitalization with abnormal chest radiograph findings, or on room air that had end organ damage defined as one of the following criteria: (i) acute kidney injury (defined as an increase in serum creatinine by $>/=0.3 \mathrm{mg} / \mathrm{dL}$ within 48 hours, or an increase in serum creatinine $>/=1.5$ times the baseline value within 7 days) [14] or (ii)acute liver injury (alanine transaminase 5 times the upper limit of normal) [15] or (iii) acute myocardial injury (troponin raised over the 99th percentile of the upper reference limit for the normal range) [16]. Severe disease in cluded patients that required non-invasive positive pressure ventilation (NIPPV) or mechanical ventilation with abnormal chest radiograph findings or patients needing NC or NRB with end organ damage as defined above.

HIV viral loads and T-lymphocyte subsets were recorded if obtained within 6 months of the admission. Viral suppression was defined as an HIV viral load $\leq 200$ copies $/ \mathrm{mL}$.

PCR testing for SARS-COV-2 was performed using either the Luminex ARIES, Abbott m2000, Hologic Panther Fusion, or Cepheid Genexpertand was used dependent of case load. The HIV-RNAand T-cell subsets were measured using the Abbott M2000 and Beckman Coulter's Aquios CL, respectively.

\section{Statistics}

Results for categorical and continuous variables were presented as frequency (\%) and median of the whole sample (IQR), accordingly. Differences between outcomes were compared using the chi-square, t-test, or Mann-Whitney $U$ test as appropriate. All analyses were conducted utilizing SPSS Software Version 25.0.

\section{Results}

This case series includes $72 \mathrm{PLWH}$ who were confirmed to have SARS-CoV-2 by RT-PCR. Within this group, 17 patients (23.6\%) were classified as mild, 31 (43.1\%) as moderate, and $24(33.3 \%)$ as severe (Figure 1). Of the patients included in the analysis, 28 (39\%) were female. Among the overall cohort, the median (IQR) age and body mass index (BMI) were 62 years (with a range of 53-68) and $26 \mathrm{~kg} / \mathrm{m}^{2}$, respectively. Patients self-identified their race as Black/African American ( $n=32,44 \%)$, white $(n=3,4 \%)$, and other $(n=37,51 \%)$. Thirty-five patients (48.6\%) had two or fewer co-morbid conditions, 29 (40.3\%) had 2-5 co-morbid conditions, and eight (11.1\%) had more than five co-morbid conditions. Eleven patients $(15 \%)$ had unsuppressed HIV viral loads, and 22 patients (31\%) had boosted protease inhibitor (PI) regimens (Table 1).

Six patients $(8.3 \%)$ were discharged directly from the emergency department (ED), and the median length of stay for patients was six days (IQR: 7). During their hospital stay, 17 patients remained on room air and 55 required oxygen supplementation (Table 1).

The primary outcome examined in this study was mortality. Twenty of the patients in this sample (27.8\%) did not survive their hospital stay. Heightened mortality rates were observed among patients with chronic kidney disease stage 3 or higher ( $55 \%$ mortality compared to $21 \%$ among patients who did 


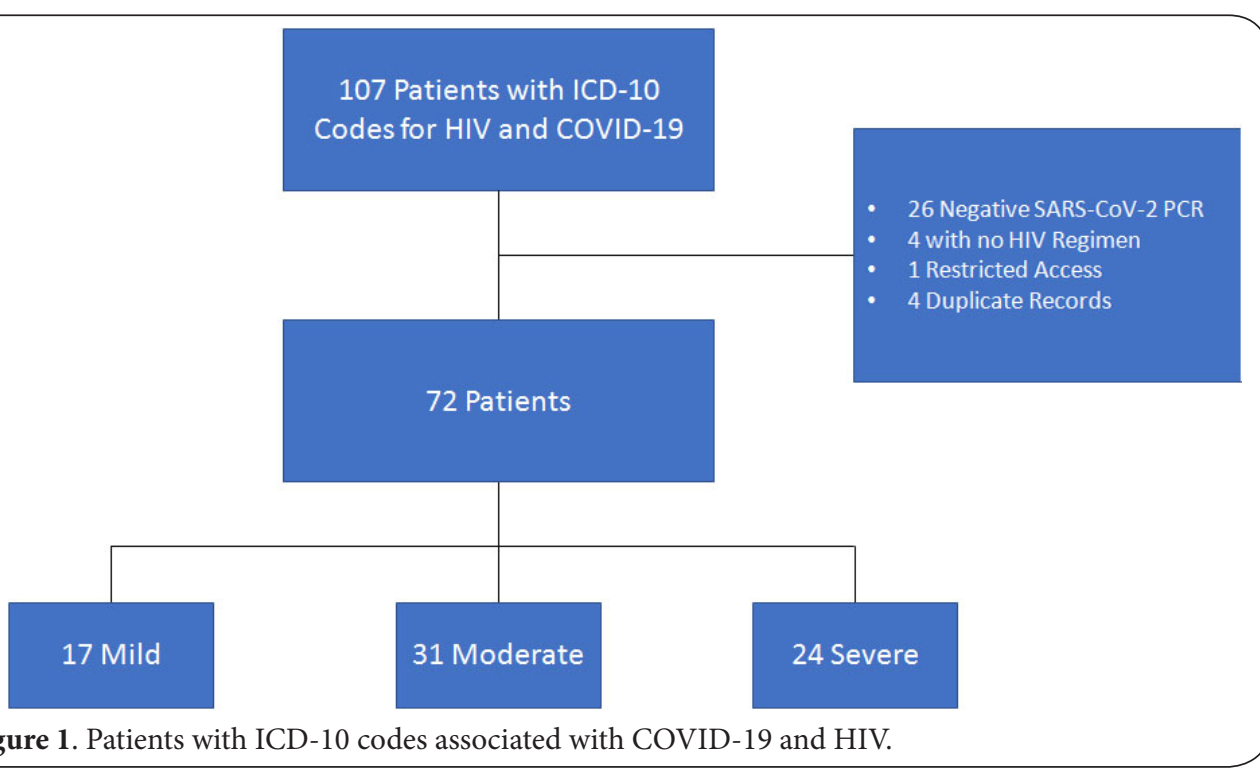

Figure 1. Patients with ICD-10 codes associated with COVID-19 and HIV.

Table 1. Patient demographics.

\begin{tabular}{|c|c|}
\hline & $\begin{array}{l}\text { Total } \\
\mathrm{N}=72 \\
\mathrm{n}(\%)\end{array}$ \\
\hline Age (years) ${ }^{a}$ & $62(16)$ \\
\hline \multicolumn{2}{|l|}{ Race } \\
\hline Black or African American & $32(44)$ \\
\hline White & $3(4)$ \\
\hline Other/Unknown & $37(51)$ \\
\hline \multicolumn{2}{|l|}{ Ethnicity } \\
\hline Spanish/Hispanic/Latino & $28(39)$ \\
\hline Not Spanish/Hispanic/Latino & $38(53)$ \\
\hline Other/Unknown & $6(8)$ \\
\hline \multicolumn{2}{|l|}{ Sex } \\
\hline Male & $44(61)$ \\
\hline Female & $28(39)$ \\
\hline BMI $\left(\mathrm{kg} / \mathrm{m}^{2}\right)^{\mathrm{a}}$ (out of 71$)$ & $27(10)$ \\
\hline \multicolumn{2}{|l|}{ Number of Commorbities } \\
\hline 0 to 2 & $31(43)$ \\
\hline 3 to 5 & $32(44)$ \\
\hline$>5$ & $9(19)$ \\
\hline \multicolumn{2}{|l|}{ Commorbidities } \\
\hline Obesity $\left(>/=30 \mathrm{~kg} / \mathrm{m}^{2}\right)$ & $23(32)$ \\
\hline Diabetes Mellitus & $29(40)$ \\
\hline Hypertension & $48(67)$ \\
\hline Coronary Artery Disease & $11(15)$ \\
\hline Heart Failure & $12(17)$ \\
\hline CKD Stage 3 or higher & $22(31)$ \\
\hline Chronic Pulmonary Disease & $29(40)$ \\
\hline Cirrhosis & $3(4)$ \\
\hline CVA & $12(17)$ \\
\hline History Active of Cancer & $19(26)$ \\
\hline Tobacco Use & $17(24)$ \\
\hline Number of Patients on Boosted Protease Inhibitors & $22(31)$ \\
\hline Length of Stay (Days) ${ }^{\mathrm{a}}$ (out of 70) & $5(7)$ \\
\hline Chest X-Ray Abnormality & $62(86)$ \\
\hline \multicolumn{2}{|l|}{ Respiratory Status } \\
\hline Room Air (RA) & $17(24)$ \\
\hline Nasal Cannula (NC) & $25(35)$ \\
\hline Non-rebreather (NRB) & $13(18)$ \\
\hline High Flow Nasal Cannula (HFNC)/Noninvasive & $2(3)$ \\
\hline positive pressure ventilation (NIPPV) & $15(21)$ \\
\hline Mechanical Ventilation (MV) & \\
\hline
\end{tabular}

Continuation of Table 1.

\begin{tabular}{|c|c|}
\hline CD4 Count (cells/uL) (out of 70) & $235(247)$ \\
\hline $\begin{array}{l}\text { Number of patients with CD4 Count (out of } 70 \text { ) } \\
\quad<200 \\
200-500 \\
>500\end{array}$ & $\begin{array}{l}26(36) \\
34(47) \\
10(14)\end{array}$ \\
\hline CD4 $\%^{\mathrm{a}}$ (out of 70 ) & $27(16)$ \\
\hline $\begin{array}{l}\text { Number of Patients with Unsuppressed HIV Viral Load } \\
\text { (out of 71) }\end{array}$ & $11(15)$ \\
\hline Gastrointestinal Issues & $26(36)$ \\
\hline $\begin{array}{l}\text { Number of Patients with LIver Enzyme Test (LFT) } \\
\text { Abnormalities }\end{array}$ & $5(7)$ \\
\hline $\begin{array}{l}\text { Number of Patients with acute Kidney Injury (AKI) } \\
\text { (out of 62) }\end{array}$ & $35(57)$ \\
\hline Number of Patients with Elevated Troponin & $12(17)$ \\
\hline Absolute Neutrophils (k/uL) ${ }^{\text {a }}$ (out of 69) & $5(5)$ \\
\hline Absolute Lymphocytes (k/uL) (out of 69) & $1.1(0.7)$ \\
\hline C-reactive Protein (C-RP) $(\mathrm{mg} / \mathrm{dL})^{\mathrm{a}}$ (out of 64) & $13(15)$ \\
\hline Interleukin-6 (IL-6) (pg/mL) ${ }^{\text {a }}$ (out of 39) & $39(100)$ \\
\hline White Blood Cell (k/uL) ${ }^{\text {a }}$ (out of 69) & $6(4)$ \\
\hline \multicolumn{2}{|l|}{ Treatment } \\
\hline Hydrochloroquine (HCQ) & $27(38)$ \\
\hline HCQ + Azithromycin & $4(6)$ \\
\hline HCQ and Steroids & $18(25)$ \\
\hline HCQ and Azithomycin and Steroids & $1(1)$ \\
\hline HCV and Steroids and IL-6 Study & $1(1)$ \\
\hline Chloroquine+Azithromycin & $2(3)$ \\
\hline Steroids & $3(4)$ \\
\hline None & $16(22)$ \\
\hline
\end{tabular}

${ }^{\mathrm{a}}$ Data are presented as median (interquartile range)

'Ten patients had ESRD and 2 did not have a serum creatinine taken during admission

not have chronic kidney disease stage 3 or higher, $p<0.01$ ) and among patients with an acute kidney injury (89\% mortality compared to $43 \%$ among patients with no acute kidney injury, $\mathrm{p}<0.01)$. Patients who did not survive had higher initial laboratory values of absolute neutrophils, interleukin 6 (IL-6), 
Lee et al. Research Journal of Infectious Diseases 2020,

http://www.hoajonline.com/journals/pdf/2052-5958-8-1.pdf

doi: $10.7243 / 2052-5958-8-1$

and C-reactive protein (CRP) than those who survived. All non-survivor patients required some oxygen supplementation (Table 2).

Two (10\%) patients in the sample received no treatment for COVID-19; the remaining patients received hydroxychloroquine, which was the local standard of care at the time. There was no difference in primary outcome between patients treated with only hydroxychloroquine and those treated with any adjuvant therapy ( $\mathrm{p}=0.42)$ (Table 2 ).

The secondary outcome examined in this study was patient need for mechanical ventilation. Fifteen patients (20.8\%) were put on mechanical ventilation during their hospital stay. Of those, three patients (20\%) were extubated and survived. Patients put on mechanical ventilation were more likely to be male $(p=0.01)$ and to have a BMI greater than $30 \mathrm{~kg} / \mathrm{m}^{2}(p<0.01)$ than those that did not require mechanical ventilation. Patients

Table 2. Results of primary and secondary endpoint.

\begin{tabular}{|c|c|c|c|c|c|c|c|}
\hline & \multicolumn{2}{|l|}{ Total } & \multicolumn{3}{|l|}{ Mortality } & \multicolumn{2}{|c|}{ Mechanical ventilation } \\
\hline & $\mathrm{N}=72$ & $\begin{array}{l}\text { Non-survivor } \\
(\mathrm{N}=20)\end{array}$ & $\begin{array}{l}\text { Survivor } \\
(\mathrm{N}=52)\end{array}$ & & Yes $(\mathrm{N}=15)$ & No $(\mathrm{N}=57)$ & \\
\hline & n (\%) & n (\%) & n (\%) & p-value & n (\%) & n (\%) & p-value \\
\hline Age (years) ${ }^{\mathrm{a}}$ & $62(16)$ & $68(15)$ & $60(15)$ & 0.052 & $61(21)$ & $62(15)$ & 0.68 \\
\hline \multicolumn{8}{|l|}{ Race } \\
\hline Black or African American & $32(44)$ & $10(50)$ & $22(42)$ & 0.51 & $9(60)$ & $23(40)$ & 0.32 \\
\hline White & $3(4)$ & $0(0)$ & $3(6)$ & & $0(0)$ & $3(5)$ & \\
\hline Other/Unknown & $37(51)$ & $10(50)$ & $27(52)$ & & $6(40)$ & $31(54)$ & \\
\hline \multicolumn{8}{|l|}{ Ethnicity } \\
\hline Spanish/Hispanic/Latino & $28(39)$ & $7(35)$ & $21(40)$ & 0.89 & $4(26)$ & $24(42)$ & 0.48 \\
\hline Not Spanish/Hispanic/Latino & $38(53)$ & $11(52)$ & $27(52)$ & & $10(67)$ & $28(49)$ & \\
\hline Other/Unknown & $6(8)$ & $4(8)$ & $2(10)$ & & $1(7)$ & $5(9)$ & \\
\hline \multicolumn{8}{|l|}{ Sex } \\
\hline Male & $44(61)$ & $11(55)$ & $33(64)$ & 0.51 & $5(33)$ & $39(68)$ & 0.01 \\
\hline Female & $28(39)$ & $9(45)$ & $19(37)$ & & $10(67)$ & $18(32)$ & \\
\hline BMI $\left(\mathrm{kg} / \mathrm{m}^{2}\right)^{\mathrm{a}}($ out of 71$)$ & $27(10)$ & $27(12)$ & $26(8)$ & 0.42 & $33(12)$ & $25(8)$ & $<0.01$ \\
\hline \multicolumn{8}{|l|}{ Number of Commorbities } \\
\hline 0 to 2 & $31(43)$ & $7(35)$ & $24(46)$ & 0.51 & $4(29)$ & $24(41)$ & 0.63 \\
\hline 3 to 5 & $32(44)$ & $10(50)$ & $22(42)$ & & $9(64)$ & $29(50)$ & \\
\hline$>5$ & $9(19)$ & $3(15)$ & $6(12)$ & & $1(7)$ & $5(9)$ & \\
\hline \multicolumn{8}{|l|}{ Commorbidities } \\
\hline Obesity $\left(>/=30 \mathrm{~kg} / \mathrm{m}^{2}\right)$ & $23(32)$ & $9(45)$ & $14(27)$ & 0.14 & $10(67)$ & $13(23)$ & $<0.01$ \\
\hline Diabetes Mellitus & $29(40)$ & $11(55)$ & $18(35)$ & 0.11 & $9(60)$ & $20(35)$ & 0.08 \\
\hline Hypertension & $48(67)$ & $15(75)$ & $33(64)$ & 0.35 & $10(67)$ & $38(67)$ & 1 \\
\hline Coronary Artery Disease & $11(15)$ & $4(20)$ & $7(14)$ & 0.49 & $2(13)$ & $9(16)$ & 0.81 \\
\hline Heart Failure & $12(17)$ & $5(25)$ & $7(14)$ & 0.24 & $3(20)$ & $9(16)$ & 0.7 \\
\hline CKD Stage 3 or higher & $22(31)$ & $11(55)$ & $11(21)$ & $<0.01$ & $7(47)$ & $15(26)$ & 0.13 \\
\hline Chronic Pulmonary Disease & $29(40)$ & $7(35)$ & $22(42)$ & 0.57 & $9(60)$ & $20(35)$ & 0.08 \\
\hline Cirrhosis & $3(4)$ & $0(0)$ & $3(6)$ & 0.27 & $0(0)$ & $3(5)$ & 0.36 \\
\hline CVA & $12(17)$ & $4(20)$ & $8(15)$ & 0.64 & $2(13)$ & $10(18)$ & 0.7 \\
\hline History Active of Cancer & $19(26)$ & $3(15)$ & $16(31)$ & 0.17 & $1(7)$ & $18(31)$ & 0.051 \\
\hline Tobacco Use & $17(24)$ & $4(20)$ & $13(26)$ & 0.6 & $3(20)$ & $14(25)$ & 0.71 \\
\hline Number of Patients on Boosted Protease Inhibitors & $22(31)$ & $3(15)$ & $19(37)$ & 0.08 & $2(13)$ & $20(35)$ & 0.10 \\
\hline Length of Stay (Days) $^{\text {a }}$ (out of 70) & $5(7)$ & $8(10)$ & $5(6)$ & 0.16 & $11(9)$ & $4(6)$ & $<0.01$ \\
\hline Chest X-Ray Abnormality & $62(86)$ & $20(100)$ & $42(81)$ & 0.04 & $15(100)$ & $47(83)$ & 0.08 \\
\hline \multicolumn{8}{|l|}{ Respiratory Status } \\
\hline Room Air (RA) & $17(24)$ & $0(0)$ & $17(33)$ & $<0.01$ & & & \\
\hline Nasal Cannula (NC) & $25(35)$ & $0(0)$ & $25(48)$ & $<0.01$ & & & \\
\hline Non-rebreather (NRB) & $13(18)$ & $7(35)$ & $6(12)$ & 0.02 & & & \\
\hline $\begin{array}{l}\text { High Flow Nasal Cannula (HFNC)/Noninvasive } \\
\text { positive pressure ventilation (NIPPV) }\end{array}$ & $2(3)$ & $1(5)$ & $1(2)$ & 0.48 & & & \\
\hline Mechanical Ventilation (MV) & $15(21)$ & $12(60)$ & $3(6)$ & $<0.01$ & & & \\
\hline CD4 Count (cells/uL) ${ }^{a}$ (out of 70) & $235(247)$ & $237(281)$ & $234(244)$ & 0.93 & $301(427)$ & $231(228)$ & 0.12 \\
\hline \multicolumn{8}{|l|}{ Number of patients with CD4 Count (out of 70) } \\
\hline$<200$ & $26(36)$ & $7(35)$ & $19(38)$ & 0.97 & $3(20)$ & $23(42)$ & 0.04 \\
\hline $200-500$ & $34(47)$ & $10(50)$ & $24(48)$ & & $7(47)$ & $27(49)$ & \\
\hline$>500$ & $10(14)$ & $3(15)$ & $7(14)$ & & $5(33)$ & $5(9)$ & \\
\hline CD4 \% ${ }^{\mathrm{a}}$ (out of 70 ) & $27(16)$ & $31(18)$ & $26(19)$ & 0.18 & $34(12)$ & $25(19)$ & 0.03 \\
\hline $\begin{array}{l}\text { Number of Patients with Unsuppressed HIV Viral } \\
\text { Load (out of 71) }\end{array}$ & $11(15)$ & $0(0)$ & $11(22)$ & 0.02 & $0(0)$ & $11(20)$ & 0.06 \\
\hline
\end{tabular}


Lee et al. Research Journal of Infectious Diseases 2020,

http://www.hoajonline.com/journals/pdf/2052-5958-8-1.pdf

doi: $10.7243 / 2052-5958-8-1$

Continuation of Table 2.

\begin{tabular}{|c|c|c|c|c|c|c|c|}
\hline & \multicolumn{2}{|l|}{ Total } & \multicolumn{3}{|l|}{ Mortality } & \multicolumn{2}{|c|}{ Mechanical ventilation } \\
\hline & $\mathrm{N}=72$ & $\begin{array}{l}\text { Non-survivor } \\
(\mathrm{N}=20)\end{array}$ & Survivor $\mathrm{N}=52$ ) & & Yes $(\mathrm{N}=15)$ & No $(\mathrm{N}=57)$ & \\
\hline & n (\%) & n (\%) & n (\%) & p-value & n (\%) & n (\%) & p-value \\
\hline Gastrointestinal Issues & $26(36)$ & $8(40)$ & $18(35)$ & 0.67 & $6(40)$ & $20(35)$ & 0.73 \\
\hline $\begin{array}{l}\text { Number of Patients with LIver Enzyme Test (LFT) } \\
\text { Abnormalities }\end{array}$ & $5(7)$ & $3(15)$ & $2(4)$ & 0.1 & $3(20)$ & $2(4)$ & 0.03 \\
\hline $\begin{array}{l}\text { Number of Patients with acute Kidney Injury } \\
(\mathrm{AKI})^{\mathbf{b}} \text { (out of } 62 \text { ) }\end{array}$ & $35(57)$ & $16(89)$ & $19(43)$ & $<0.01$ & $13(93)$ & $22(46)$ & $<0.01$ \\
\hline Number of Patients with Elevated Troponin & $12(17)$ & $6(30)$ & $6(12)$ & 0.06 & $4(27)$ & $8(14)$ & 0.24 \\
\hline Absolute Neutrophils (k/uL) ${ }^{a}$ (out of 69) & $5(5)$ & $6(8)$ & $4(4)$ & $<0.01$ & $9(7)$ & $4(3)$ & 0.01 \\
\hline Absolute Lymphocytes (k/uL) (out of 69) & $1.1(0.7)$ & $0.9(.8)$ & $1.1(0.7)$ & 0.11 & $1(0.5)$ & $1(0.8)$ & 1.00 \\
\hline C-reactive Protein $(\mathrm{C}-\mathrm{RP})(\mathrm{mg} / \mathrm{dL})^{\mathrm{a}}$ (out of 64$)$ & $13(15)$ & $17(13)$ & $9(14)$ & 0.01 & $17(17))$ & $11(14)$ & 0.08 \\
\hline Interleukin-6 (IL-6) (pg/mL) ${ }^{\text {a }}$ (out of 39) & $39(100)$ & $96(262)$ & $26(54)$ & $<0.01$ & $59(268)$ & $34(60)$ & 0.12 \\
\hline White Blood Cell (k/uL) ${ }^{\text {a }}$ (out of 69) & $6(4)$ & $6(6)$ & $6(3)$ & 0.14 & $7(8)$ & $6(3)$ & 0.13 \\
\hline Treatment & $27(38)$ & $9(33)$ & $18(67)$ & 0.42 & $4(27)$ & $23(40)$ & 0.33 \\
\hline Hydrochloroquine (HCQ) & $4(6)$ & $1(5)$ & $3(6)$ & 0.9 & $1(7)$ & $3(5)$ & 0.83 \\
\hline HCQ + Azithromycin & $18(25)$ & $7(35)$ & $11(21)$ & 0.22 & $7(47)$ & $11(19)$ & 0.03 \\
\hline HCQ and Steroids & $1(1)$ & $0(0)$ & $1(2)$ & 0.53 & $0(0)$ & $1(2)$ & 0.61 \\
\hline HCQ and Azithomycin and Steroids & $1(1)$ & $1(5)$ & $0(0)$ & 0.1 & $1(7)$ & $0(0)$ & 0.05 \\
\hline HCV and Steroids and IL- 6 Study & $2(3)$ & $0(0)$ & $2(4)$ & 0.37 & $1(7)$ & $1(2)$ & 0.3 \\
\hline Chloroquine+Azithromycin & $3(4)$ & $0(0)$ & $3(6)$ & 0.27 & $1(7)$ & $2(4)$ & 0.59 \\
\hline Steroids & $16(22)$ & $2(10)$ & $14(27)$ & 0.12 & $0(0)$ & $16(28)$ & 0.03 \\
\hline None & & & & & & & \\
\hline
\end{tabular}

${ }^{a}$ Data are presented as median (interquartile range)

${ }^{\mathrm{b}}$ Ten patients had ESRD and 2 did not have a serum creatinine taken during admission

on mechanical ventilation were also more likely to have had acute liver $(p=0.03)$ and kidney $(p<0.01)$ injury than those not on mechanical ventilation (Table 2 ).

\section{Discussion}

For PLWH, antiretroviral therapy is associated with reductions in morbidity and mortality from both HIV-related and non-HIV related causes [17]. It has been hypothesized that the causal relationships between HIV and co-morbidities and co-infections are based on immunosuppression and increased susceptibility to infectious agents, a dysregulated immune response to pathogens, and increased levels of inflammation. Therefore, some have speculated that PLWH would have increased risk of COVID-19 and sequelae. Conversely, PLWH may be protected from COVID-19 because of a blunted immune response to SARS-CoV-2, which may mitigate the risk of severe cytokine mediated disease. The risk of having poorly controlled HIV infection relative to virologic suppression and a reconstituted immune system is similarly unclear. In this study, it was expected that patients with controlled HIV infection would have improved survival rates in the setting of COVID-19. Contrary to this hypothesis, the study data demonstrate that all non-surviving patients had suppressed HIV viral loads with CD4 counts ranging from 27 to 1,111 cells/uL.

The hypothesized role of inflammation in the pathogenesis of COVID-19 [18] is supported in that non-surviving patients in this study had higher levels of CRP and IL- 6 than those who survived. Consistent with previously published literature, there was no difference in mortality among patients who received antiretroviral therapy that included a boosted protease inhibitor [19] or hydroxychloroquine [20].

This study cohort represents a relatively small proportion of PLWH hospitalized with COVID-19 and does not include those who may have died prior to arriving at the hospital. Further, non-surviving patients with Do-Not-Resuscitate/DoNot-Intubate (DNR/DNI) advanced directives were included in the mechanical ventilation analysis as requiring other forms of supplemental oxygen, and their HIV viral loads and CD4 counts were therefore attributed to non-mechanically ventilated patients who did not survive. It is important to acknowledge that both HIV viral loads and CD4 counts fluctuate over time and are not perfect markers of long-term adherence. For example, CD4 counts may decline in the case of an acute infection. This limitation was partially addressed by including patient HIV viral load and CD4 count values within six months prior to admission when available. Additionally, the cohort was derived from billing codes, and it is therefore possible that some patients with HIV and COVID-19 may have been excluded from the sample.

\section{Conclusion}

PLWH in the United States are a diverse and heterogeneous population with varied demographic, social, and clinical characteristics. Our findings suggest that a detectable HIV 
Lee et al. Research Journal of Infectious Diseases 2020,

http://www.hoajonline.com/journals/pdf/2052-5958-8-1.pdf

doi: $10.7243 / 2052-5958-8-1$

viral load or low CD4+ count did not correlate to increased mortality or mechanical ventilation. Co-morbidities that have been associated with poor COVID-19 outcomes are common among PLWH. Larger studies examining PLWH and their experiences with COVID-19 are needed to further describe patient characteristics that may portend an unfavorable prognosis.

\section{Competing interests}

The authors declare that they have no competing interests.

\section{Authors' contributions}

\begin{tabular}{|l|c|c|c|c|c|c|c|}
\hline Authors' contributions & PJL & SS & NR & LG & CC & RG & RB \\
\hline Research concept and design & $\checkmark$ & $\checkmark$ & -- & $\checkmark$ & -- & $\checkmark$ & $\checkmark$ \\
\hline Collection and/or assembly of data & $\checkmark$ & -- & -- & -- & $\checkmark$ & -- & $\checkmark$ \\
\hline Data analysis and interpretation & $\checkmark$ & $\checkmark$ & $\checkmark$ & $\checkmark$ & -- & $\checkmark$ & $\checkmark$ \\
\hline Writing the article & $\checkmark$ & $\checkmark$ & $\checkmark$ & $\checkmark$ & -- & $\checkmark$ & $\checkmark$ \\
\hline Critical revision of the article & $\checkmark$ & $\checkmark$ & $\checkmark$ & $\checkmark$ & -- & $\checkmark$ & $\checkmark$ \\
\hline Final approval of article & $\checkmark$ & $\checkmark$ & $\checkmark$ & $\checkmark$ & -- & $\checkmark$ & $\checkmark$ \\
\hline Statistical analysis & -- & -- & $\checkmark$ & -- & -- & -- & -- \\
\hline
\end{tabular}

\section{Acknowledgments}

We would like to thank Nelida DeJesus and Krystal G. Rodriguez for helping us build the algorithm for identifying patients. We would like to acknowledge Dr. Yitz Goldstein and Dr. Yanhua Wang in the virology department at Montefiore Medical Center.

\section{Publication history}

EIC: Ishtiaq Qadri, King Abdul Aziz University, Saudi Arabia.

Received: 10-Aug-2020 Final Revised: 28-Oct-2020

Accepted: 05-Nov-2020 Published: 24-Nov-2020

\section{References}

1. Holshue ML, DeBolt C, Lindquist S, et al. First case of 2019 novel coronavirus in the United States. New England Journal of Medicine 2020.

2. Centers for Disease Control and Prevention (CDC). Cases in the U.S. https://www.cdc.gov/coronavirus/2019-ncov/cases-updates/cases-in-us. html (accessed September 23, 2020).

3. Garg S. Hospitalization rates and characteristics of patients hospitalized with laboratory-confirmed coronavirus disease 2019-COVID-NET, 14 States, March 1-30, 2020. MMWR Morbidity and mortality weekly report 2020; 69.

4. Du R-H, Liang L-R, Yang C-Q, et al. Predictors of mortality for patients with COVID-19 pneumonia caused by SARS-CoV-2: a prospective cohort study. European Respiratory Journal 2020; 55.

5. Centers for Disease Control and Prevention (CDC). Estimated HIV incidence and prevalence in the United States, 2010-2016. HIV surveillance supplemental report 2019; 24 (No. 1). 2019.

6. Centers for Disease Control and Prevention (CDC). What to Know About HIV and COVID-19. In: National Center for Immunization and Respiratory Diseases (NCIRD) DoVD, ed. 2020.

7. Gallant J, Hsue PY, Shreay S, Meyer N. Comorbidities among US patients with prevalent HIV infection-a trend analysis. The Journal of infectious diseases 2017; 216: 1525-33.

8. Gervasoni C, Meraviglia P, Riva A, et al. Clinical features and outcomes of HIV patients with coronavirus disease 2019. Clinical Infectious Diseases 2020.

9. Blanco JL, Ambrosioni J, Garcia F, Martínez E, Soriano A, Mallolas J, Miro JM. COVID-19 in patients with HIV: clinical case series. The Lancet HIV 2020; 7: e314-e6.

10. Zhao J, Liao X, Wang H, Wei L, Xing M, Liu L, Zhang Z. Early virus clearance and delayed antibody response in a case of COVID-19 with a history of co-infection with HIV-1 and HCV. Clinical Infectious Diseases 2020.
11. Zhu F, Cao Y, Xu S, Zhou M. Co-infection of SARS-CoV-2 and HIV in a patient in Wuhan city, China. Journal of Medical Virology 2020.

12. New York City Department of Health and Mental Hygiene. HIV Surveillance Annual Report, 2018. New York, NY, 2019.

13. NYC Health. COVID-19: Data. 2020. https://www1.nyc.gov/site/doh/ covid/covid-19-data.page (accessed June 26 2020).

14. Khwaja A. KDIGO clinical practice guidelines for acute kidney injury. Nephron Clinical Practice 2012; 120(4): c179-c84.

15. National Institutes of Health. LiverTox: clinical and research information on drug-induced liver injury. https://livertox.nih.gov 2017.

16. Daubert MA, Jeremias A. The utility of troponin measurement to detect myocardial infarction: review of the current findings. Vascular health and risk management 2010; 6: 691.

17. Group ISS. Initiation of antiretroviral therapy in early asymptomatic HIV infection. New England Journal of Medicine 2015; 373: 795-807.

18. Mehta P, McAuley DF, Brown M, Sanchez E, Tattersall RS, Manson JJ, Collaboration HAS. COVID-19: consider cytokine storm syndromes and immunosuppression. Lancet (London, England) 2020; 395: 1033.

19. Cao B, Wang Y, Wen D, et al. A trial of lopinavir-ritonavir in adults hospitalized with severe Covid-19. New England Journal of Medicine 2020.

20. Magagnoli J, Narendran S, Pereira F, Cummings TH, Hardin JW, Sutton SS, Ambati J. Outcomes of hydroxychloroquine usage in United States veterans hospitalized with Covid-19. Med 2020.

\section{Citation:}

Lee P, Sirichand S, Corro LG, Gutierrez NR, Cruz C, Grossberg R and Bernardo RM. HIV and COVID-19

Co-Infection in an Urban Setting. Res J Infect Dis. 2020; 8:1. http://dx.doi.org/10.7243/2052-5958-8-1 